\title{
RASGANDO O VERBO: A CRÍTICA FEMINISTA À TEOLOGIA DA LIBERTAÇÃO.
}

RIBEIRO, Claudio (org.). Rasgando o verbo: A crítica feminista à Teologia da Libertação. São Paulo: Fonte Editorial, 2016, 123 p.

Elaine Martins Donda*

A presente obra é apresentada por seu organizador, Claudio Ribeiro, como resultado de suas reflexões decorrentes de um curso sobre questões de método em Teologia, com enfoque crítico à Teologia Latino-Americana da Libertação. Em suas avaliações, ele procurou destacar a rica produção teológica latino-americana como legado para novas gerações, tendo em vista temas como a importância da vida comunitária de fé e o compromisso cristão em relação à defesa da vida, solidariedade, bem como, formas de inclusão e cidadania, exercício dos direitos humanos e cuidado com a criação.

Desenvolve sua análise numa perspectiva ad intra, ou seja, com questionamentos pautados no seu próprio "compromisso com os princípios práticos e teóricos fundamentais dessa visão teológica, sobretudo a preferência que o Evangelho nos exige que se dê às pessoas pobres" (Claudio RIBEIRO, 2016, p. 9).

Ribeiro pontua três questões como desafios emergentes ao pensamento teológico latino-americano. A primeira trata da necessidade de alargamento metodológico para melhor compreensão da complexidade social e maior integração às perspectivas plurais de análise. A segunda reside em maior articulação entre racionalidade teológica

* Doutoranda em Ciências da Religião pela Universidade Metodista de São Paulo (UMESP). Mestra em Educação pela Universidade Metodista de São Paulo (UMESP). Graduada em História pela Faculdade de Educação Ciências e Artes Dom Bosco e em Teologia pela Universidade Metodista de São Paulo (UMESP). 
latino-americana e subjetividade humana, o que pressupõe reformulações mais autênticas de espiritualidade. A terceira circunda em torno da importância em aprofundar a valorização do pluralismo religioso como possibilidade de fortalecimento da democracia e práticas ecumênicas em prol dos direitos humanos, bem como, da terra.

O autor intui que "tais desafios podem ser iluminados pela produção de teólogas como Ivone Gebara, Elsa Tamez, Maria Clara Bingemer e Marcella Althaus-Reid, em especial as reflexões em torno das temáticas relativas à espiritualidade, às questões de gênero e à busca de lógicas inclusivas e de justiça social e de valorização da sexualidade" (Claudio RIBEIRO, 2016, p. 12). Nessa perspectiva, organiza o livro em duas partes: a primeira, com quatro capítulos para apresentar cada uma das teólogas e suas respectivas contribuições acerca do método teológico, tendo em vista que essas mulheres possuem um horizonte comum - pensar nossa realidade, a partir da perspectiva teológica latino-americana.

"Rasgando o verbo. A crítica feminista à Teologia da Libertação" principia com Ivone Gebara, importante teóloga brasileira, que ainda jovem ingressou na ordem das Irmãs de Nossa Senhora - Cônegas de Santo Agostinho. Trabalhou na pastoral popular ao lado de Dom Hélder Câmara, entre comunidades pobres no Nordeste brasileiro, e lecionou por quase duas décadas no Instituto Teológico do Recife. Na década de 90, enfrentou processo e condenação eclesiástica por suas críticas às doutrinas morais da Igreja Católica e por tratar com certa abertura e sensibilidade humanitária temas como aborto e métodos contraceptivos. É autora de uma densa lista de publicações entre livros e artigos.

Ribeiro aborda o questionamento de Ivone Gebara a partir das análises de Gênero que a autora faz acerca da realidade social, tanto nas dimensões práticas quanto teóricas.

Para ela, é essencial evidenciar o lugar que as mulheres pobres ocupam na sociedade. Nesse sentido, deve-se atentar para as armadilhas econômicas, pois se cria a "ilusão de que a globalização abriu espaços para as mulheres, mas de fato são espaços de trabalho com baixa remuneração e marcados pela instabilidade" (Ivone GEBARA, 2010, p. 17). Quanto às análises científicas, indica a relevância em questionar o universalismo das ciências, a fim de superar o idealismo masculino, tendo em consideração 
a existência de uma vida plural comum homens e mulheres, pois, até a segunda metade do século XX, refletiu-se "a partir do humano masculino e nele incluíram o feminino como realidade subalterna ou inteiramente dependente do masculino" (Ivone GEBARA, 2010, p. 19).

Alude à importância de se criar uma ética plural, a fim de perceber a existência de várias realidades e formas de interpretar o mundo e que a humanidade é uma interdependência ou "mistura na qual os diferentes elementos que nos constituem, elementos conhecidos e desconhecidos, formam uma teia complexa de movimentos ou uma teia de fios que se entrecruzam para se manter" (Ivone GEBARA, 2010, p. 68).

No âmbito teológico, quanto à opção pelos pobres, Ivone Gebara interpreta como devidas às críticas da Teologia da Libertação, feitas especialmente às teologias europeias. Mas no que se refere ao feminismo, assevera "era demonizado pelos teólogos da libertação que nos incitavam a não dividir a luta e, de certa forma, jurar fidelidade aos ideais libertários masculinos da Teologia da Libertação" (Ivone GEBARA, 2010, p. 210).

Quanto a esses grandes ideais masculinos embasados no socialismo, adverte que não podem dar conta de responder às demandas das relações sociais do tempo presente, portanto, deve-se reconhecer a não linearidade da História diante da complexidade do mundo e valorizar devidamente a vida cotidiana, não reduzida somente no direito ao trabalho ou em aquisições materiais, antes, considerar como relevantes a liberdade de pensamento, os bens simbólicos, a autodeterminação, as possibilidades criativas, o prazer, a diversidade sexual e cultural.

Ainda, a partir das análises de Gênero, enfatiza a urgência de uma revisão das imagens e linguagens androcêntricas de Deus e nos impele a transgredir a ordem estabelecida para vivenciarmos uma espiritualidade concreta, com profundo respeito a todos os seres criados e à preservação da vida.

O segundo capítulo é atribuído a Elsa Tamez, mexicana, de tradição protestante, teóloga e biblista reconhecida no cenário teológico mundial. Ainda jovem, migrou para a Costa Rica, para efetivar seus estudos teológicos na Universidade Bíblica Latino-Americana. Trabalhou como docente, tem destaque na criação de uma extensa rede de teologia feminista da libertação, e possui ampla experiência no campo ecumênico. 
A profundidade de suas reflexões teológicas tem forte articulação com sua própria trajetória de vida, em especial, os anos tensos das guerras civis que ocorreram na Nicarágua, El Salvador e Guatemala.

Ribeiro pontuou especialmente duas perspectivas do pensamento teológico de Elsa Tamez: a crítica feminista aos processos sociais e eclesiais e a crítica teológica à economia política na perspectiva dos pobres - uma marca crucial na Teologia da Libertação.

A reflexão bíblica de Tamez prioriza o contexto das mulheres, numa interpretação mais inclusiva e justa e em sintonia com o espírito dos textos bíblicos; sua abordagem é pautada na revelação divina, tema central que possibilita "compreender os significados de fé, graça, amor, paz, pecado e salvação" (Elsa TAMEZ, 1980, p. 7-8) em oposição aos valores culturais sedimentados no patriarcalismo e ao modelo hegemônico da economia capitalista e seus impactos na vida cotidiana. Com base na Teologia da Libertação, privilegiou a justificação pela fé, a partir da ótica de pessoas e grupos excluídos da dinâmica social, tendo como pressuposto que "todos, não uns poucos, têm direito a viver dignamente como sujeitos, porque a vida é dom de Deus" (Elsa TAMEZ, 1995, p. 262).

Sua perspectiva de justificação pela fé rompe com a teologia tradicional de que a justificação centra-se na morte de Jesus na cruz; para Tamez, essa lógica é excludente e com aspectos sacrificialistas das experiências religiosas e sociais, acarretando em vitimização das pessoas. Enfatiza que a questão não é a morte, mas sim a ressurreição o lugar central da justificação divina. Uma visão sem o peso sacrificialista que resulta em boas novas, sem lugar para sacrifícios humanos e se constitui em fonte de dignidade para as pessoas.

Assim, a justificação pela fé deve ser compreendida como a ação histórica de Deus, a partir da gratuidade, que inclui pessoas excluídas, e que redunda em empoderamento, pois a força superior e ao mesmo tempo interna ao ser humano o impulsiona a crer e enfrentar injustiças sociais. Nessa proposta hermenêutica, os seres humanos tornam-se sujeitos históricos, são livres da injustiça e tomam consciência de que portam a imagem de Deus; contudo, não esquecem o passado, condição existencial para não submeter outras pessoas à exclusão. 
O terceiro capítulo nos traz a brasileira Maria Clara Lucchetti Bingemer, uma das destacadas teólogas da atualidade, com diversas obras publicadas. É leiga católica e professora da Pontifícia Universidade Católica do Rio de Janeiro. Tem sido referência no campo acadêmico por suas pesquisas, em especial temas da mística, da teologia feminista e de aspectos sistemáticos como escatologia, cristologia e pneumatologia, também alteridade e espiritualidade ecumênica. Bingemer destacou-se, desde os anos de 1980, na reflexão sobre os temas teológicos, vistos na perspectiva da mulher e sempre procurou contribuir em espaços eclesiais, pois, para ela, formar cristãos líderes e protagonistas na sociedade é parte da missão da igreja.

A autora evidencia a salvação como um dom do Espírito de Deus dentro dos seres humanos e o mistério da revelação. Para tanto, com base no pensamento agostiniano, indica que "é impossível entender, captar completamente o Deus Uno e Trino da nossa fé. Mas é possível, sim, conhecê-lo na medida em que ele mesmo revela seu Mistério aos sedentos e amorosos que o buscam" (Maria Clara Lucchetti BINGEMER; Vitor Galdino FELLER, 2003, p. 14-15).

Quanto ao valor da mística e da pluralidade, pontos destacados na presente obra, adverte sobre a necessidade de considerar as experiências religiosas atuais, marcadas por constantes transformações sociais e econômicas. Nesse sentido, os símbolos religiosos passam por ressignificações, alterando as formas e expressões tradicionais; contudo, "a busca de Deus e o desejo de uma espiritualidade crescem em igual proporção, desembocando em muitas praias que não são mais apenas nem principalmente as igrejas históricas" (Maria Clara Lucchetti BINGEMER, 2013, p. 98).

$\mathrm{Na}$ verdade, deve-se pensar em pluralidades, não isentas de formas de massificação, de padronização e de uniformização das vivências religiosas inseridas em modelos econômicos de consumo que constantemente serão fonte de conflitos criativos e que desafiarão as análises sociais em continuamente buscar alternativas de paz e alteridade, tendo como horizonte a visão ecumênica que propõe abertura e acolhimento ao outro.

O quarto capítulo é dedicado à argentina Marcella Althaus-Reid, teóloga protestante que desenvolveu ampla experiência de trabalho 
popular, ancorado no método dialógico elaborado por Paulo Freire, em comunidades empobrecidas na Argentina e na Escócia.

Como docente e pesquisadora na Universidade de Edimburgo, abordou temas relacionados à teologia feminista, à teologia queer, à Teologia da Libertação, ao debate entre marxismo e teologia, pós-modernidade e globalização. Segundo Ribeiro, "provavelmente por conta da radicalidade e profundidade temática, não se tornou bem divulgada nos espaços latino-americanos" (Claudio RIBEIRO, 2016, p. 59). Marcella morreu em 20 de fevereiro de 2009, em Edimburgo, na Escócia, com apenas 57 anos de idade.

Aprofundou a temática da sexualidade, estudos de Gênero, hermenêutica bíblica e desenvolveu a teologia queer, um enfoque teológico que centra o tema da libertação na condição de discriminação e afirmação das pessoas de orientação LGBT para propor uma nova visão sobre Deus, em suas palavras, um Deus Queer que "foge dos regimes da 'normalidade' construída” (Marcella ALTHAUS-REID, 2004, p. 92).

Marcella Althaus-Reid ficou internacionalmente conhecida com sua obra Teologia Indecente: perversões teológicas em sexo, gênero e política. A autora parte da pressuposição de que toda teologia implica uma prática sexual e política, pois tais questões estão correlacionadas. Ao fazer uma teologia sexual indecente em meio aos processos de globalização, visa demonstrar como as formas hegemônicas, em especial a heterossexualidade patriarcal, condicionaram o pensamento e relações econômicas em países empobrecidos.

Nesse sentido, assegura "uso a metáfora da sexualidade porque acho que é uma metáfora que nos mostra a concretude da vida. Quando convido as mulheres a fazerem uma teologia sem calcinhas [teologia sin ropa interior], pretendo chamá-las a fazer uma teologia metafórica, provocativa, subversiva. E, mais que tudo, acho importante a perspectiva ética na elaboração teológica. É indispensável fazer uma teologia a partir de seu contexto, uma coisa que os teólogos da libertação se esqueceram de fazer" (Marcella ALTHAUS-REID, 2004, p. 90).

Diante da realidade vivida por grupos sexuais marginalizados, a autora propõe outra compreensão cristológica para além da estabelecida - o modelo Bi/Christ, ou Cristo bissexual. 
Assevera que "A Teologia da Libertação não disponibilizou cadeiras para as mulheres pobres ou para gays pobres - ou pelo menos, não o fez espontaneamente. $O$ projeto inclusivo afirmou-se mediante políticas de exclusão que determinaram a identidade dos pobres", (Marcella ALTHAUS-REID, 2006, p. 458) esses idealizados como masculinos, uma categoria geral que apaga a diversidade sexual. Declara que as críticas feitas à Teologia da Libertação partem do fato de que essa teologia é a sua base.

Para a autora, a Teologia da Libertação não percebeu a subversão dos códigos sexuais e de Gênero presentes na vida das mulheres nos contextos de pobreza e suas lutas por dignidade. Desse modo, é preciso redescobrir a face de Deus, considerando as identidades sexuais dessas pessoas excluídas que vivem diferenciadas formas de relacionamentos amorosos.

A segunda parte de "Rasgando o verbo..." tem a reprodução de um texto de cada uma das quatro teólogas, os quais juntos compõem uma "significativa interpelação ao método teológico" (Claudio RIBEIRO, 2016, p. 7).

"Marx em um bar gay: A Teologia Indecente como uma reflexão sobre a Teologia da Libertação e a Sexualidade", de Marcella Althaus-Reid, aponta para o fato de que a Teologia da Libertação não conseguiu distanciar-se do modelo de sexualidade ideológico - a heterossexualidade. Nesse sentido, é preciso ser indecente para superar discriminações.

"Corpo, o novo ponto de partida da Teologia", de Ivone Gebara, é uma crônica que nos convida a reconhecer o corpo como primeira realidade que temos. Nesse lugar está o desafio de superar medos, em especial o medo ideológico patriarcal que nos foi imposto em relação a Eva, a Mãe dos viventes.

“Teologia e espiritualidade", de Maria Clara Lucchetti Bingemer, aborda o novo rosto plural que surge na Pós-Modernidade e a implicação em reconhecer e dialogar com a pluralidade religiosa, no sentido de que a espiritualidade deve ser tratada com atenção pela teologia, pois abarca diferentes experiências religiosas, e cada uma delas considera-se a verdadeira experiência de Deus. 
E, para encerrar a presente obra, o poema "A festa como uma experiência sagrada", de Elsa Tamez, sobre a Ceia do Senhor. Nessa festa especial, não existem pessoas marginalizadas. Esse é o modo como se deve pensar a Eucaristia, um festejo humano em que se sente a presença divina, um compromisso solidário, inter-humano com pobres, humanidade e Deus.

"Rasgando o verbo..." constitui-se em importantes vozes femininas contidas no interior da Teologia da Libertação, que nos falam de modo contundente acerca da urgência em revisar o método teológico, especialmente no que tange às imagens androcêntricas de Deus, a fim de considerar as complexidades da vida cotidiana e de fé, com suas plurais expressões religiosas, tendo como horizonte o profundo respeito por todos os seres criados e rompendo com as formas de exclusão e injustiças.

\section{REFERÊNCIAS}

ALTHAUS-REID, Marcella. "Demitologizando a Teologia da Libertação: reflexões sobre poder, pobreza e sexualidade". In: SUSI, Luiz Carlos (org.). Teologia para Outro Mundo Possível. São Paulo: Paulinas, 2006.

. "Entrevista [por Sandra Duarte de Souza e Luiza Tomita]”. Mandrágora, IX, (10), 2004, p. 90-92.

BINGEMER, Maria Clara Lucchetti. O mistério e o mundo. Rio de Janeiro: Rocco, 2013. BINGEMER, Maria Clara Lucchetti; FELLER, Vitor Galdino. Deus-amor: a graça que habita em nós. São Paulo: Paulinas. Valencia: Siquem, 2003.

GEBARA, Ivone. Vulnerabilidade, Justiça e Feminismos. São Bernardo do Campo: Nhanduti Editora, 2010.

RIBEIRO, Claudio (org.). Rasgando o verbo: A crítica feminista à Teologia da Libertação. São Paulo: Fonte Editorial, 2016.

TAMEZ, Elsa. A Bíblia dos oprimidos: a opressão na teologia bíblica. São Paulo: Paulinas, 1980.

. Contra toda condenação: a justificação pela fé partindo dos excluídos. São Paulo: Paulinas, 1995.

Submetido em: 6-4-2017

Aceito em: 6-6-2017 